\title{
Cerebral blood flow in Alzheimer's disease
}

This article was published in the following Dove Press journal:

Vascular Health and Risk Management

19 October 2012

Number of times this article has been viewed

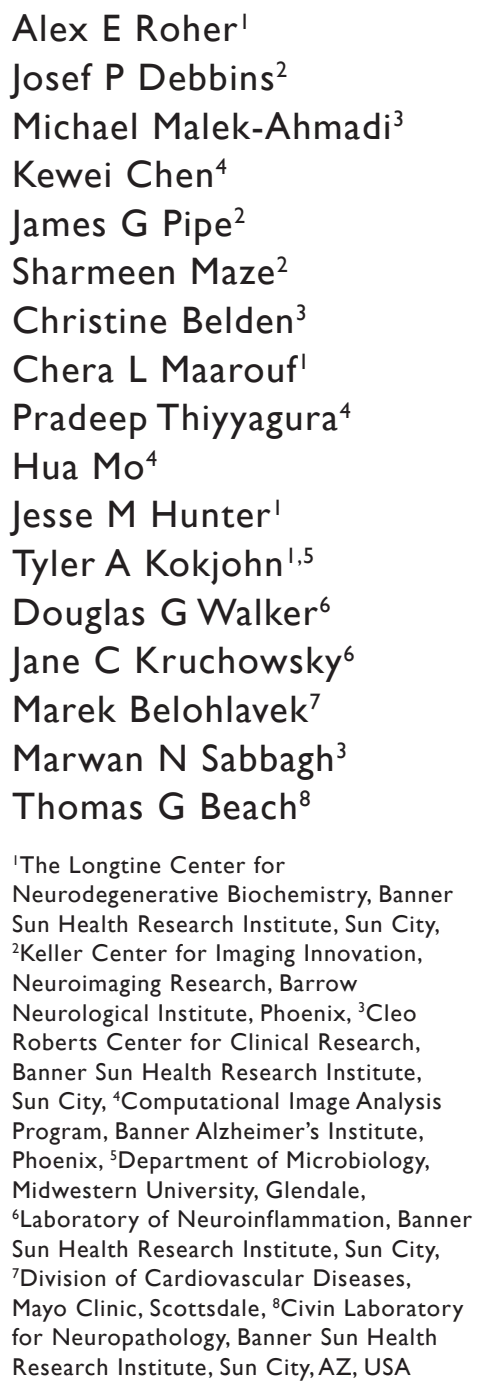

Correspondence: Alex E Roher Banner Sun Health Research Institute, 10515 West Santa Fe Dr, Sun City, AZ 8535I, USA

$\mathrm{Tel}+\mathrm{I} 6238325465$

Fax + I 6238325698

Email alex.roher@bannerhealth.com
Background: Alzheimer's disease (AD) dementia is a consequence of heterogeneous and complex interactions of age-related neurodegeneration and vascular-associated pathologies. Evidence has accumulated that there is increased atherosclerosis/arteriosclerosis of the intracranial arteries in $\mathrm{AD}$ and that this may be additive or synergistic with respect to the generation of hypoxia/ischemia and cognitive dysfunction. The effectiveness of pharmacologic therapies and lifestyle modification in reducing cardiovascular disease has prompted a reconsideration of the roles that cardiovascular disease and cerebrovascular function play in the pathogenesis of dementia.

Methods: Using two-dimensional phase-contrast magnetic resonance imaging, we quantified cerebral blood flow within the internal carotid, basilar, and middle cerebral arteries in a group of individuals with mild to moderate $\mathrm{AD}(\mathrm{n}=8)$ and compared the results with those from a group of age-matched nondemented control (NDC) subjects $(n=9)$. Clinical and psychometric testing was performed on all individuals, as well as obtaining their magnetic resonance imagingbased hippocampal volumes.

Results: Our experiments reveal that total cerebral blood flow was $20 \%$ lower in the AD group than in the NDC group, and that these values were directly correlated with pulse pressure and cognitive measures. The AD group had a significantly lower pulse pressure (mean AD 48, mean NDC $71 ; P=0.0004)$. A significant group difference was also observed in their hippocampal volumes. Composite z-scores for clinical, psychometric, hippocampal volume, and hemodynamic data differed between the AD and NDC subjects, with values in the former being significantly lower $(t=12.00, \mathrm{df}=1, P=0.001)$ than in the latter.

Conclusion: These results indicate an association between brain hypoperfusion and the dementia of AD. Cardiovascular disease combined with brain hypoperfusion may participate in the pathogenesis/pathophysiology of neurodegenerative diseases. Future longitudinal and larger-scale confirmatory investigations measuring multidomain parameters are warranted.

Keywords: Alzheimer's disease, cerebral blood flow, brain hypoperfusion, two-dimensional phase-contrast magnetic resonance imaging, brain morphometric analyses, atherosclerosis, arteriosclerosis, cognitive impairment

\section{Introduction}

Alzheimer's disease (AD) presently affects more than 5 million Americans, and this number is projected to increase to 16 million by the year $2050 .{ }^{1}$ Diagnostic and therapeutic interventions that can prevent, delay the onset, or slow the progression of this form of dementia are urgently needed. AD is definitively diagnosed based on quantitative neuropathologic criteria reflecting the profuse deposition of amyloid plaques and neurofibrillary tangles. The prominence of these lesions has made them 
obvious therapeutic targets, but successful interventions to prevent or remove amyloid plaques have not had the anticipated commensurate impacts on dementia. ${ }^{2,3}$ It has been suggested that chronic brain hypoperfusion and consequent hypoxia/ischemia play a direct role in the pathogenesis of $\mathrm{AD}$ or promote the development of this dementia., ${ }^{4,5}$ A consensus is emerging that $\mathrm{AD}$ is a heterogeneous amalgam of multiple age-related neurodegenerative factors and vascularassociated pathologies.

It is irrefutable that a healthy cardiovascular system is indispensible for brain development, function, and survival. To meet metabolic demands efficiently, the blood flow to the brain needs to be approximately $750 \mathrm{~mL}$ per minute or about $50 \mathrm{~mL} / 100 \mathrm{~mL}$ of brain tissue per minute. ${ }^{6,7}$ Cerebral perfusion pressure is primarily generated by an efficient cardiac output, patent elastic arterial walls modulated by the microvascular resistance of the brain, and adequate venous drainage. In addition, a series of hemorheologic events and conditions needs to be extant, such as adequate blood pressure, blood viscosity, blood flow velocity, and appropriate vascular resistance of the brain vasculature. In a recent report, Nation et al observed that elevated pulse pressure was correlated with the severity of cerebrovascular disease found post mortem. ${ }^{8}$ In a large brain perfusion study carried out by the Rotterdam Study group, it was found that individuals with low total brain perfusion showed significantly larger white matter lesion volumes relative to those with high total brain perfusion. ${ }^{9}$ Other epidemiologic studies have also found an association between decreased pulse pressure and the risk of AD. ${ }^{10}$

Single-photon emission computed tomography and arterial spin labeling-magnetic resonance imaging perfusion studies, adjusted for related gray matter atrophy, have shown dysfunctional cerebral blood flow in individuals with AD. ${ }^{1-13}$ The value of arterial spin labeling-magnetic resonance imaging, a promising technique for the quantification of cerebral blood flow, has been recently reviewed by Alsop et al. ${ }^{14}$ The consensus indicates that the parietal and frontal cortices, the precuneus, and the posterior cingulate are the predominant areas with altered cerebral blood flow in AD. The latter two brain regions reflect the global perfusion state of watershed areas because they are irrigated by terminal branches of the pericallosal artery, a branch from the anterior cerebral artery, and/or the posterior cerebral arteries. ${ }^{15}$ In general, a large body of data from in vivo functional imaging studies suggests that profound alterations in cerebral blood flow, glucose utilization, and oxidative metabolism are observable in the early stages of AD. ${ }^{16-24}$ Magnetic resonance imaging measurements of brain atrophy and white matter hyperintensities, as well as diffusion tensor magnetic resonance imaging and cerebral blood flow estimated by arterial spin labeling-magnetic resonance imaging and/or two-dimensional phase-contrast magnetic resonance imaging (2D-PC MRI) are promising tools for the preclinical assessment and diagnosis of mild cognitive impairment and $\mathrm{AD}$, and for longitudinal evaluation of therapeutic interventions deployed against dementia progression.

The cardiovascular contributions to vascular cognitive impairment and dementia have been recently reviewed by an authoritative study group representing the American Heart Association/American Stroke Association and endorsed by the American Academy of Neurology and the Alzheimer's Association. ${ }^{5}$ The group emphasized the need for transdisciplinary, translational, and transactional studies to understand better the complicated interactions that exist between vascular and $\mathrm{AD}$ pathologies.

In this preliminary study, we measured cerebral blood flow in the internal carotid, basilar, and middle cerebral arteries in a group of individuals with mild to moderate $\mathrm{AD}$ and compared the results with those from a group of age-matched nondemented control (NDC) subjects using 2D-PC MRI. We sought any potential correlation between cerebral blood flow volumes, pulse pressure, and cognitive measurements. A composite z-score for each individual in the study was performed by combining clinical, psychometric, hippocampal volumes, and hemodynamic data to evaluate and potentially discover correlations between cardiovascular parameters, brain morphology, and clinical information.

\section{Materials and methods Human subjects}

Nine NDC individuals and eight subjects with mild to moderate AD participated in this study. The NDC cases were enrolled at the Brain and Body Donation Program of Banner Sun Health Research Institute, Sun City, Arizona. ${ }^{25}$ The AD subjects were recruited from the private practice of MNS. All protocols used in this study were approved by internal review boards at Banner Sun Health Research Institute and St Joseph's Hospital Medical Center. All individuals signed an informed consent form for the clinical and psychometric arms of the study, as well as for the magnetic resonance imaging scanning procedures. Demographic and clinical characteristics, including age, height, weight, body mass index, gender, apolipoprotein $\mathrm{E}$ genotype, and $\mathrm{AD}$ disease duration since onset of clinical symptoms are shown in 


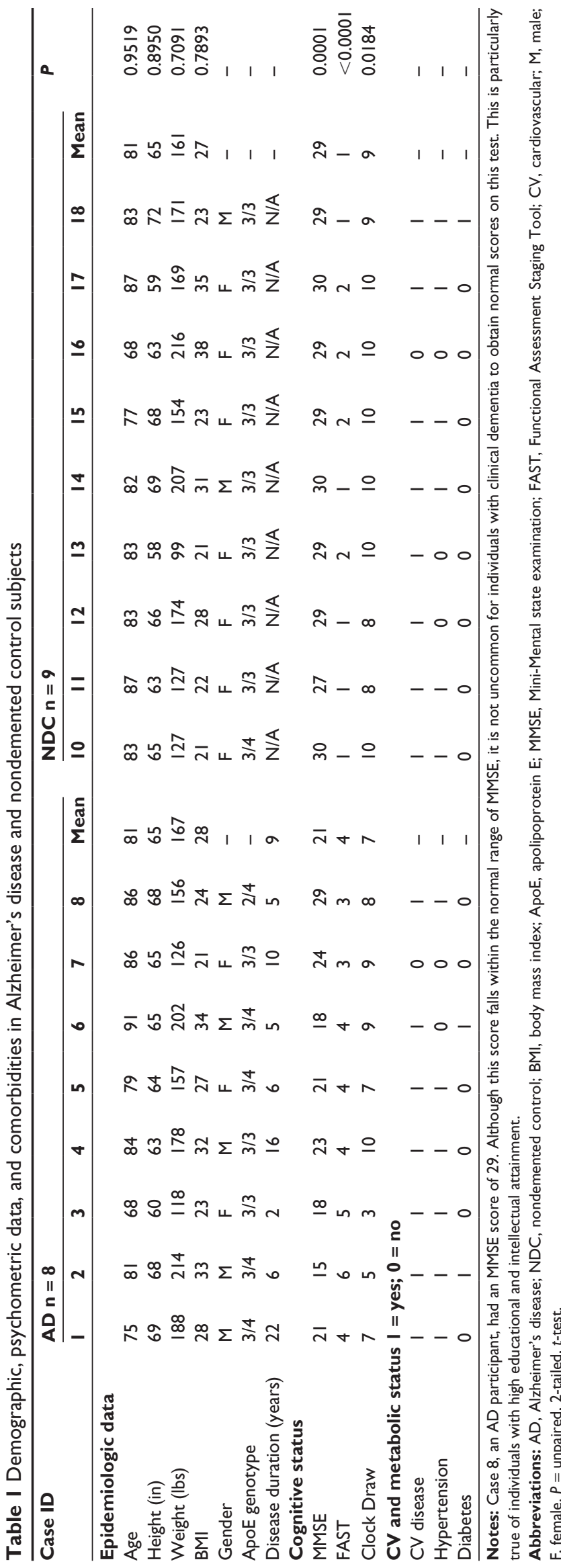

Table 1 . The presence of hypertension and diabetes, as well as cardiovascular disease encompassing coronary artery disease (angioplasty, stenting, coronary artery bypass graft), myocardial infarction, angina, atrial fibrillation, arrhythmias, valvulopathy, cardiomyopathy, and peripheral vascular disease was also investigated, and the results for each subject in the study are given in Table 1. The presence or absence of cardiovascular-related diseases is given in a binary format suitable for statistical analysis. Systolic and diastolic blood pressures, pulse pressure, and pulse rate are shown in Table 2. A detailed list of past and present medical history and list of medications taken by each of the individuals involved in this study is shown in Table 3.

The diagnosis for all participants was made by consensus with a physician and neuropsychologist. The NDC cohort had no demonstrable cognitively based limitations of activities of daily living, had intact cognition based upon neuropsychologic assessment, and a clinical dementia rating of 0 . Subjects had at least a 6th grade education or work history exclusive of mental disabilities. Prospective interview of the participant and a medical records review were used to exclude anyone with a brain-related neurologic or significant psychiatric illness. Examples of excluded conditions included Parkinson's or other neurodegenerative diseases, mental disability, epilepsy, cerebral infarction or hemorrhage, multiple sclerosis, brain tumor, major depressive disorder (unipolar or bipolar), schizophrenia, traumatic brain injury, and substance abuse/dependence. Subjects diagnosed with delirium (Diagnostic and Statistical Manual of Mental Disorders, Fourth Edition) or with conditions such as blindness/deafness were also excluded. The AD subjects met the National Institute of Neurological and Communicative Disorders and Stroke-Alzheimer's Disease and Related Disorders Association criteria for a clinical diagnosis of probable or possible $\mathrm{AD} .{ }^{26}$

\section{Psychometric testing}

All subjects involved in the study were psychometrically tested using: the Mini-Mental State Examination (MMSE) for measuring working memory, language, praxis, orientation, and memory; ${ }^{27}$ the Functional Assessment Staging (FAST) test that contains 16 stages, with stage 1 marking no difficulties for the patient and stage 7 (f) describing a patient who is unable to hold his/her head up; ${ }^{28,29}$ and the Clock Drawing Test for assessment of visuospatial functions, receptive language, numeric knowledge, working memory, and executive functions. This measure is scored on a 10-point scale, with lower scores reflecting greater impairment. ${ }^{30,31}$ Global and 


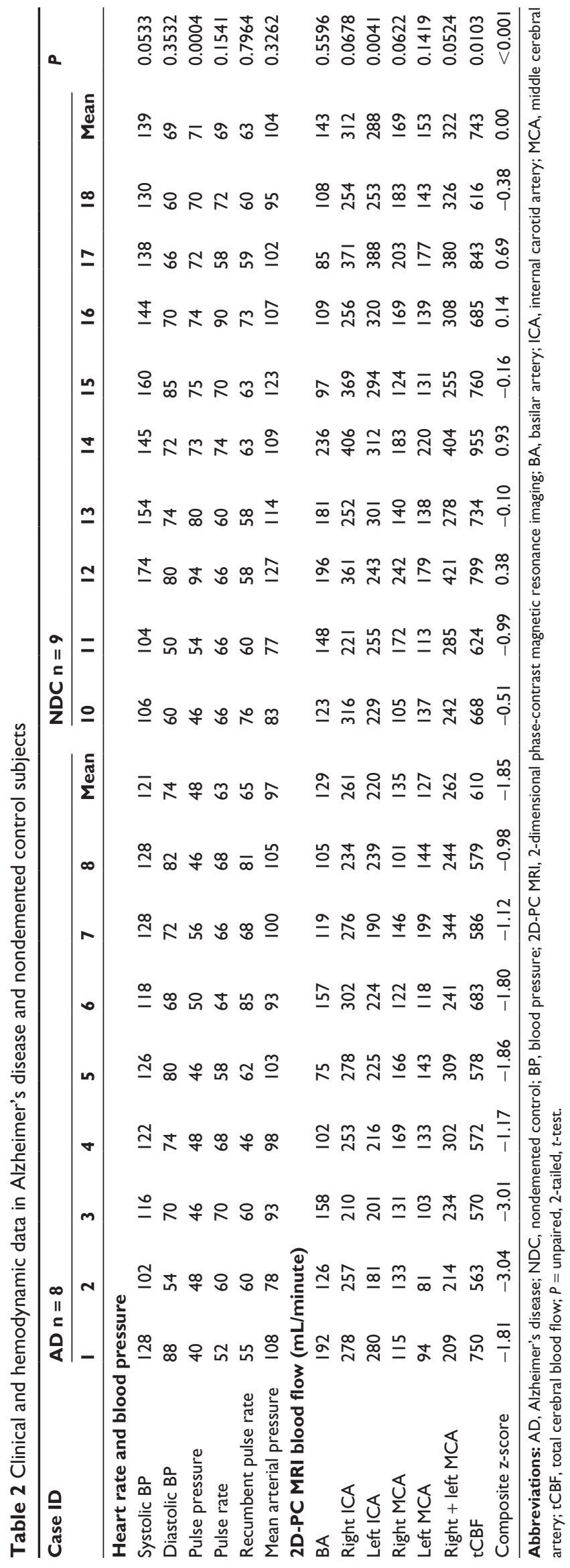

functional assessments were performed by investigators blinded to the motor and cognitive scores. The results of the psychometric evaluations are shown in Table 1.

\section{MRI}

All scans were performed at the Keller Center for Imaging Innovation located on the campus of St Joseph's Hospital and Medical Center in Phoenix, Arizona, using a GE (General Electric Healthcare, Waukesaha, WI) Signa HD $\times 3 \mathrm{~T}$ system (revision 14.0) employing an eight-channel head coil. Subjects provided their informed consent prior to scanning as per the approved study institutional review board. After patient landmarks were obtained, a three-plane localizer scan was performed, followed by a low-resolution two-dimensional dataset acquired for ASSET (array spatial and sensitivity encoding technique) calibration (parallel imaging). A magnitude-only three-dimensional time of flight (TOF) magnetic resonance imaging was performed axially, using ASSET to accelerate the scan. This provided a detailed view of the patient vasculature in order to prescribe the subsequent two-dimensional phase contrast flow scans. The parameters of the three-dimensional TOF magnetic resonance imaging were (axial, field of view $=18.0 \mathrm{~cm}$, locs $=32, \mathrm{BW}=31.25 \mathrm{kHz}, \mathrm{TE}=\min , \mathrm{TR}=21.0 \mathrm{msec}$, res $384 \times 224$ in-plane, fat sat, slice accel $=1.0$, phase accel $=2.0$, superior sat, excitation used ramp pulse, images reconstructed to 512). Total scan time was 8 minutes and 9 seconds. This was followed by a two-dimensional phase contrast slice, with through-plane phase contrast flow encoding. The two-dimensional slice was oriented orthogonal to each vessel location as identified in the previous three-dimensional TOF magnetic resonance imaging scan. A total of five vessel measurements (separate scans) were made using this sequence: basilar artery, right and left internal carotid arteries, and right and left middle cerebral arteries. Total cerebral blood flow was calculated by adding the right and left internal carotid arteries and basilar artery flow values. The scan parameters for this sequence were: two-dimensional, CINE, flow comp, flip $=20$, field of view $=14.0$, thick $=5 \mathrm{~mm}, \mathrm{BW}=62.50$, resolution $128 \times 128,16$ phases, $\mathrm{TE}=\min , \mathrm{TR}=18 \mathrm{msec}, \mathrm{NEX}=1$, venc $=100 \mathrm{~cm} / \mathrm{sec}$. Because the scans are synchronized to the patient heartbeat, with 16 cardiac phases acquired, the scan time was variable for each patient, but on the order of 2 minutes for each two-dimensional acquisition. Subsequently, a volumetric T1 scan was obtained, by standard three-dimensional IR-SPGR with a scan time of 8 minutes and 8 seconds. Scan parameters were sagittal, TI $=450$, 
Table 3 Health conditions of study subjects and current medications

\begin{tabular}{|c|c|}
\hline Case ID & \\
\hline I & $A D$ \\
\hline Health conditions & AF, angioplasty, CABG, CAD, coronary stenting, HL, HT, OA, sleep apnea, TBI w/o LOC (2010) \\
\hline \multirow[t]{2}{*}{ Medications } & Aricept ${ }^{\circledR}$, aspirin, digoxin, ferrous sulfate, furosemide, hydralazine, lisinopril, metoprolol, multivitamins, Namenda ${ }^{\circledR}$, \\
\hline & Omega-3, $\mathrm{KCl}$, sertraline, Zocor ${ }^{\circledR}$ \\
\hline 2 & $A D$ \\
\hline Health conditions & $\begin{array}{l}\text { AF, chronic renal insufficiency, DM, fatty liver, } \mathrm{HT} \text {, melanoma of right eye requiring radiation, paraproteinemia, } \\
\text { proteinuria }\end{array}$ \\
\hline Medications & Actos $^{\circledR}$, Aricept $^{\circledR}$, aspirin, Lasi ${ }^{\circledR}$, Levemir $^{\circledast}$, lisinopril, multivitamins, Namenda ${ }^{\circledR}$, Prozac $^{\circledast}$, Risperda $^{\circledR}$ \\
\hline 3 & $A D$ \\
\hline Health conditions & $\begin{array}{l}\text { Anxiety, CABG, CAD, defibrillator, depression, } \mathrm{HT} \text {, hypercholesterolemia, MI, osteoporosis, PTCA with stents, } \\
\text { rheumatoid arthritis, systemic lupus erythematosus }\end{array}$ \\
\hline Medications & Aricept ${ }^{\circledR}$, vitamin BI2, Cozaar $^{\circledR}$, Dilacor ${ }^{\circledR}$, hydrocodone \\
\hline 4 & $A D$ \\
\hline Health conditions & $\begin{array}{l}\text { Angiography with angioplasty carotid artery, benign prostatic hypertrophy, } \mathrm{CAD}, \mathrm{HT}, \mathrm{MI} \text {, transurethral resection } \\
\text { of prostate }\end{array}$ \\
\hline Medications & Aricept $\mathrm{t}^{\circledR}$, aspirin, diltiazem, multivitamins, Namenda ${ }^{\circledR}$, Niaspan $^{\circledR}$, Plavix $^{\circledR}$, Prozac $^{\circledR}$, simvastatin \\
\hline 5 & $A D$ \\
\hline Health conditions & HT, hypercholesterolemia, \\
\hline Medications & Advil $^{\circledR}$, aspirin, Diovan ${ }^{\circledast}$, Excelon ${ }^{\circledast}$, Fosamax ${ }^{\circledast}$, multivitamin, Namenda $^{\circledR}$, Toprol ${ }^{\circledR}$, Vesicare ${ }^{\circledR}$, vitamin E, Zocor ${ }^{\circledR}$ \\
\hline 6 & $A D$ \\
\hline Health conditions & $\mathrm{AF}$, bradycardia, diet-controlled DM, heart murmur, hypothyroidism, OA \\
\hline Medications & Aricept $^{\circledR}$, aspirin, Coumadin ${ }^{\circledR}$, Detrol $^{\circledR}$, Exelon $^{\circledR}$, Lexapro $^{\circledR}, \mathrm{Namenda}^{\circledR}$, Tofranil $^{\circledR}$ \\
\hline 7 & $A D$ \\
\hline Health conditions & Cancer, diverticulosis, osteoporosis \\
\hline Medications & $\begin{array}{l}\text { Acidophilus, aspirin, B complex, Caltrate }{ }^{\circledR}, \text { Citraca }^{\circledR}, \text { Evista }^{\circledR} \text {, glucosamine }+ \text { chondroitin, K-flex }{ }^{\circledR} \text {, multivitamins, } \\
\text { Namenda }^{\circledR} \text {, Razadyne }{ }^{\circledR} \text {, vitamin } D\end{array}$ \\
\hline 8 & $A D$ \\
\hline Health conditions & AF, arthritis, CAD, cholecystectomy, concussion, COPD, glaucoma, HT, osteoporosis, sleep apnea \\
\hline Medications & 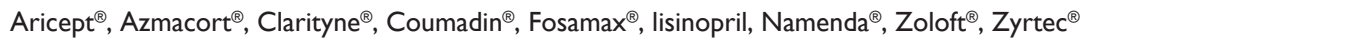 \\
\hline 10 & NDC \\
\hline Health conditions & Angina, breast cancer, $\mathrm{HL}, \mathrm{HT}$, hypothyroidism, migraine, $\mathrm{OA}$ \\
\hline Medications & Calcium citrate + multivitamins, Cardizem ${ }^{\circledast}$, levothyroxine, omeprazole, pilocarpine, Xalatan ${ }^{\circledR}$, Zocor $^{\circledR}$ \\
\hline 11 & NDC \\
\hline Health conditions & Cataract, back pain, essential tremor, hearing impairment, $\mathrm{HL}, \mathrm{HT}$, hyperthyroidism, stress incontinence \\
\hline Medications & Atenolol, Ditropan ${ }^{\circledR}$, enalapril, Zocor ${ }^{\circledR}$ \\
\hline 12 & NDC \\
\hline Health conditions & $\begin{array}{l}\text { Abdominal aneurysm, back pain, Bell's palsy, essential tremor, hearing impairment, hypercholesterolemia, } \\
\text { hypothyroidism, osteoporosis, OA, vitamin B } 12 \text { deficiency }\end{array}$ \\
\hline Medications & $\begin{array}{l}\text { Aspirin, calcium citrate }+ \text { vitamin D, fish oil, Fosamax }{ }^{\circledR} \text {, levothyroxine, multivitamins, } \text { Tylenol }^{\circledR} \text {, vitamin } B \mid 2 \text {, vitamin } C \text {, } \\
\text { Zocor }^{\circledR}\end{array}$ \\
\hline 13 & NDC \\
\hline Health conditions & Hypercholesterolemia, osteoporosis \\
\hline Medications & Calcium citrate + vitamin D, fish oil, flax seed oil, Metamucil $^{\circledR}$, multivitamins \\
\hline 14 & NDC \\
\hline Health conditions & $\begin{array}{l}\text { DM type 2, cataract, } \mathrm{HT} \text {, macular degeneration, OA, prostate cancer, prostatectomy, total knee arthroplasty, urinary } \\
\text { incontinence, valve replacement }\end{array}$ \\
\hline Medications & Allopurinol, aspirin, fish oil, folic acid, glipizide, Januvia ${ }^{\circledR}$, multivitamins, Ocuvite ${ }^{\circledR}$, potassium citrate, Toprol ${ }^{\circledR}$ \\
\hline 15 & NDC \\
\hline Health conditions & $\begin{array}{l}\text { Cataract, chronic bronchitis, degenerative joint disease, depression, fibromyalgia, HL, HT, osteoarthritis, osteoporosis, } \\
\text { peripheral neuropathy, RLS, rotator cuff repair, sciatica, syncope, Valley fever }\end{array}$ \\
\hline Medications & 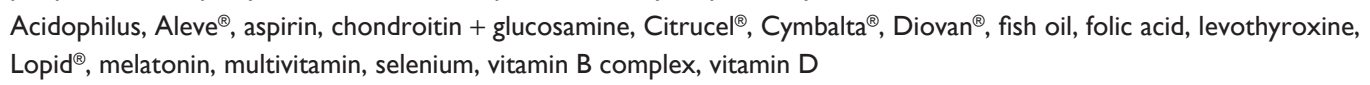 \\
\hline 16 & NDC \\
\hline Health conditions & Allergy (NOS), asthma, meningitis, restless leg syndrome, TBI? \\
\hline Medications & 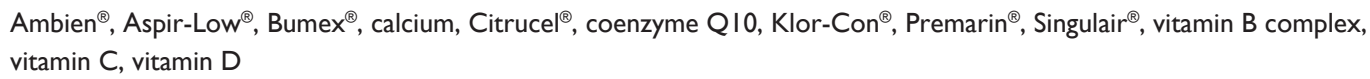 \\
\hline
\end{tabular}


Table 3 (Continued)

\begin{tabular}{|c|c|}
\hline Case ID & \\
\hline 17 & NDC \\
\hline Health conditions & $\begin{array}{l}\text { CAD, cholecystectomy, herniorrhaphy, hypercholesterolemia, irregular arrhythmia, nerve resection for dysphonia, } \\
\text { PTCA with angioplasty, spasmodic dysphonia }\end{array}$ \\
\hline Medications & Lipitor $^{\circledR}$, atenolol, aspirin, tramadol, Prozac ${ }^{\circledR}$, Effexor $^{\circledR}$, lisinopril, iron, Dulcolax ${ }^{\circledR}$, Celexa $^{\circledR}$, Detrol ${ }^{\circledR}$ \\
\hline 18 & NDC \\
\hline Health conditions & $\begin{array}{l}\text { CAD, cataract extraction, cardiomyopathy (NOS), coronary stenting, COPD, benign prostatic hyperplasia, depression, } \\
\text { DM type } 2 \text {, HT, hypothyroidism, MI, PLMS, post polio syndrome, Valley fever }\end{array}$ \\
\hline Medications & $\begin{array}{l}\text { Aspirin, Plavix }{ }^{\circledR}, \text { Prinivi }^{\circledR}, \text { Coreg }^{\circledR}, \text { Aciphex }^{\circledR} \text {, Lantus } \\
{ }^{\circledR} \text {, albuterol, multivitamins, Lipitor } \\
\text { Synthroid }^{\circledR} \text {, amlodipine, fexofenadine, }\end{array}$ \\
\hline
\end{tabular}

Abbreviations: AD, Alzheimer's disease; AF, atrial fibrillation; CABG, coronary artery bypass graft; CAD, coronary artery disease; COPD, chronic obstructive pulmonary disease; DM, diabetes mellitus; HL, hyperlipidemia; HT, hypertension; LOC, loss of consciousness; NDC, nondemented control; NOS, not otherwise specified; OA, osteoarthritis; PTCA, percutaneous transluminal coronary angioplasty; RLS, restless legs syndrome; TBI, traumatic brain injury.

flip $=8$, field of view $=26.0, \mathrm{TE}=\mathrm{min}, \mathrm{TR}=900 \mathrm{msec}$, slices $=170$, thick $=1.2 \mathrm{~mm}, \mathrm{BW}=31.25 \mathrm{kHz}$, freq $=224$, phase $=224, \mathrm{NEX}=0.75$. Finally, a volumetric T2 scan was obtained using a prototype three-dimensional fast spin-echo scan (now commercially available). Scan time was 6 minutes and 6 seconds, with scan parameters set as follows: FRFSE-XL, fast-recovery; field of view $=26.0$, slices $=128$, thick $=1.2, \mathrm{TE}=$ minutes, $\mathrm{TR}=6200 \mathrm{msec}$, $\mathrm{BW}=31.25 \mathrm{kHz}$, freq $=224$, phase $=224$.

The 2D-PC MRI flow data collected were processed using the ReportCard ${ }^{\mathrm{TM}}$ analysis software provided by the scanner vendor (General Electric Healthcare). Phase contrast results from the 2D-PC MRI datasets were loaded into the software, which automatically plots the velocities of each of 16 cardiac phases (time points over the heartbeat). This plot of the velocities over the cardiac cycle was then analyzed by integrating the area of the velocity curve over the vessel area, which determines flow and is in a superior and outward direction for the arteries of interest in the brain. This value was recorded as the flow value for each of the measured arteries in $\mathrm{mL}$ per minute.

\section{Voxel-based morphometry and FreeSurfer image analyses}

We used the SPM8 (http://www.fil.ion.ucl.ac.uk/spm/) voxelbased morphometry version 8 (VBM8) toolbox to process the volumetric $\mathrm{T} 1$ magnetic resonance imaging data to generate segmented gray matter images for each study participant and to deform them into the Montreal Neurological Institute brain template coordinate space. We examined the difference in regional gray matter volumes between $\mathrm{AD}$ patients and NDC subjects in the parahippocampus and hippocampal regions using the family-wise error correction procedure to correct for multiple comparisons in the regions. In addition to this voxel-based analysis, we also estimated the hippocampal volumes. To do this, we used FreeSurfer software (surfer.nmr. mgh.harvard.edu/) to perform cortical reconstruction and volumetric segmentation, as described previously. ${ }^{32-43}$ Briefly, this FreeSurfer processing includes removal of nonbrain tissue using a hybrid watershed/surface deformation procedure, ${ }^{43}$ automated Talairach transformation, segmentation of the subcortical white matter and deep gray matter volumetric structures (including hippocampus, amygdala, caudate, putamen, ventricles), ${ }^{36,37}$ intensity normalization, ${ }^{44}$ tessellation of the gray matter-white matter boundary, automated topology correction, ${ }^{35,45}$ and surface deformation following intensity gradients for optimal placement of the gray/white and gray/cerebrospinal fluid borders at the location where the greatest shift in intensity defines the transition to the other tissue class. ${ }^{32-34}$ FreeSurfer morphometric procedures have been demonstrated to show good test-retest reliability across scanner manufacturers and across field strengths. ${ }^{41} \mathrm{We}$ examined the differences between the two groups in terms of the absolute hippocampal volume and in terms of the relative volumes as the percentage of total intracranial volume.

\section{Pulse pressure}

Right and left brachial artery blood pressures were obtained with each subject in the seated position after 5 minutes of rest. The difference between the systolic and diastolic pressures was defined as pulse pressure.

\section{Apolipoprotein E genotyping}

Samples of cells were collected from each participant by rubbing a SK-1 swab (Isohelix Inc, London, UK) on the inside of cheeks for 30-60 seconds. The swab was broken off into a collecting tube, immediately stored at $-20^{\circ} \mathrm{C}$, and processed in a single batch. DNA was isolated from each swab using the Isohelix DNA isolation kit. In brief, a proteinase K solution was added directly to each tube and samples were digested 
for one hour at $37^{\circ} \mathrm{C}$. The liquid was recovered, transferred to new tubes, and DNA was precipitated with equal volumes of isopropanol. DNA was recovered by centrifugation and dissolved in Tris-ethylenediamine tetra-acetic acid buffer. Yields of DNA ranged from 2-6 $\mathrm{g}$ g per sample. DNA $(0.5 \mu \mathrm{g})$ from each sample was used for polymerase chain reaction amplification using specific primers. The genotype of each case was identified by the gel electrophoresis pattern of DNA bands following digestion with the Hhal restriction enzyme. ${ }^{46}$

\section{Statistical analysis and composite z-score}

A composite z-score integrating several parameters, including total cerebral blood flow (the sum of the right and left internal carotid arteries and basilar artery flow values), pulse pressure (numeric difference between systolic and diastolic blood pressure), body mass index, Clock Draw, and MMSE was calculated. Also included in the composite z-score were FreeSurfer volumetric magnetic resonance imaging values for left hippocampal volume, right hippocampal volume, 1000* relative left hippocampal volume, $1000^{*}$ relative right hippocampal volume, and total hippocampal volume. The raw scores for each parameter were converted into z-scores, and an average of all the $\mathrm{z}$-scores was calculated for each individual. This average is referred to as the composite $\mathrm{Z}$-score. Z-scores for each parameter were calculated by subtracting the NDC group mean from the raw score and dividing by the standard deviation of the NDC group. The directionality of each variable was considered so that the $\mathrm{z}$-score reflected whether an increase or decrease in the variable would be indicative of AD.

Given that the sample size for each clinical group was relatively small, the nonparametric Kruskal-Wallis test was used for group comparisons. The Kruskal-Wallis test was used to discern group differences in composite z-score between the AD and NDC groups, with statistical significance determined by $P$ values of $\leq 0.05$. Similar analyses were also conducted to determine if the composite z-score differed significantly by gender and apolipoprotein E $\varepsilon 4$ carrier status. In addition, correlation analysis between pulse pressure, body mass index, and cerebral blood flow variables was carried out to determine the degree of association between these variables. Chi-square analyses were performed to determine if significant differences in gender and apolipoprotein E $\varepsilon 4$ frequency were present in the study sample.

\section{Results}

The demographic and clinical characteristics of the study sample are displayed in Table 1. The AD and NDC groups did not differ significantly with respect to age (KruskalWallis $=0.002, P=0.96)$. There were no significant differences in gender frequency $\left(\chi^{2}=2.49\right.$, df $\left.=1, P=0.11\right)$; however, the proportion of apolipoprotein E $\varepsilon 4$ carriers in the AD group was significantly greater than in the NDC group $\left(\chi^{2}=4.90, \mathrm{df}=1, P=0.03\right)$. The mean body mass index in the AD and NDC populations was almost identical (Table 1). Group comparisons of MMSE, FAST, and Clock Draw demonstrated significant statistical differences in the expected directions (Table 1) between the two study groups.

Cardiovascular disease was the most prevalent pathology among the study participants, with only one individual in each group (AD patient 7 and NDC patient 16) free of cardiovascular-related ailments (Table 1). Twelve of the 17 individuals in the study suffered from hypertension (Table 1). We observed a significant difference in mean systolic blood pressure between the AD and NDC subjects $(P=0.05)$, resulting in a lower pulse pressure in the AD group (mean AD 48 versus mean NDC 71; $P=0.0004$, Table 2). Interestingly, there were no statistically significant differences in pulse rate or diastolic blood pressure between the two groups ( $P=0.15$ and $P=0.35$, respectively). All subjects with hypertension were receiving antihypertensive therapy, ie, calcium channel blockers, beta-blockers, angiotensinconverting enzyme inhibitors, and/or angiotensin receptor blockers (Table 3 ).

In order to assess cerebral blood flow in our AD and NDC subjects, 2D-PC MRI measurements (mL per minute) were taken from the basilar, right and left internal carotid, and right and left middle cerebral arteries (Table 2). Mean cerebral blood flow values for each of the arteries studied were lower in the AD group than in the NDC group (Table 2). The left internal carotid, and right and left middle cerebral arteries, as well as total cerebral blood flow, represented by addition of the basilar artery and left and right internal carotid artery, showed statistically significant group differences (Table 2). Mean total cerebral blood flow in the NDC population was $743 \mathrm{~mL}$ per minute, which is within the expected range for normal blood flow. In contrast, the AD group had a mean value of $610 \mathrm{~mL}$ per minute, representing about $20 \%$ less than the mean NDC value, suggesting reduced brain perfusion in the AD group. Because our sample numbers were small, we carried out further statistical analyses of the individual arteries and found the following: left internal carotid artery [Kruskal-Wallis $=8.90(\mathrm{df}=1), P=0.003]$; right internal carotid artery [Kruskal-Wallis $=4.08(\mathrm{df}=1), P=0.04]$; left middle cerebral artery [Kruskal-Wallis $=1.82(\mathrm{df}=1)$, $P=0.18]$; right middle cerebral artery [Kruskal-Wallis $=8.03$ 
$(\mathrm{df}=1), P=0.005]$; and basilar artery (Kruskal-Wallis $=0.15$ $(\mathrm{df}=1), P=0.70)$.

Correlations of pulse pressure with body mass index and cerebral blood flow variables are shown in Table 4. Pulse pressure was moderately correlated with all cerebral blood flow measures, with the exception of the basilar artery, which showed a weak correlation. Body mass index did not correlate with pulse pressure (Table 4). Statistical correlations between pulse pressure, MMSE, and Clock Draw, as well as correlations between arterial blood flow, MMSE, and Clock Draw are shown in Table 5, and with the exception of the basilar and right middle cerebral artery, all values are moderately correlated.

To determine if apolipoprotein $\mathrm{E} \varepsilon 4$ carrier status has any effect on pulse pressure and total brain blood flow, a nonparametric Kruskal-Wallis test was used for both comparisons, revealing no significant difference in total brain blood flow [Kruskal-Wallis $=1.46(\mathrm{df}=1), P=0.23]$. However, pulse pressure was significantly different between apolipoprotein E $\varepsilon 4$ carriers and noncarriers [Kruskal-Wallis $=8.03(\mathrm{df}=1)$, $P=0.005]$, with apolipoprotein E $\varepsilon 4$ noncarriers having higher pulse pressure.

Voxel-based morphometry found that AD subjects had significantly less volume than NDC subjects in the left parahippocampal region (uncorrected $P<0.001$ and corrected $P=0.021)$. FreeSurfer volumetric analyses were also carried out, and it was found that $\mathrm{AD}$ subjects had significantly less volume in both the right and left hippocampal regions (Table 6). Intracranial volume was not significantly different between the AD and NDC groups $(P=0.23)$

The blood flow data of the individual arteries were combined with other measures in order to characterize more accurately the contribution of other cardiovascular variables to our overall hypothesis. For a final statistical analysis of clinical, psychometric, morphometric, and hemodynamic data, a composite z-score including several parameters (total cerebral blood flow, pulse pressure, hippocampal volume, body mass

Table 4 Correlation of pulse pressure with BMI and cerebral blood flow variables

\begin{tabular}{ll}
\hline & Pulse pressure \\
\hline BMI & 0.09 \\
BA & 0.24 \\
Right ICA & 0.52 \\
Left ICA & 0.55 \\
Right MCA & 0.57 \\
Left MCA & 0.54 \\
tCBF & 0.62 \\
\hline
\end{tabular}

Abbreviations: BMI, body mass index; $\mathrm{BA}$, basilar artery; ICA, internal carotid artery; MCA, middle cerebral artery; tCBF, total cerebral blood flow.
Table 5 Correlation of psychometric testing with pulse pressure and cerebral blood flow variables

\begin{tabular}{lll}
\hline & MMSE & Clock \\
\hline Pulse pressure & 0.63 & 0.46 \\
BA & 0.01 & -0.10 \\
Right ICA & 0.41 & 0.48 \\
Left ICA & 0.64 & 0.55 \\
Right MCA & 0.33 & 0.19 \\
Left MCA & 0.61 & 0.54 \\
Right + left MCA & 0.53 & 0.42 \\
tCBF & 0.52 & 0.47 \\
\hline
\end{tabular}

Note: FAST score was not used due to its categorical nature.

Abbreviations: MMSE, Mini-Mental state examination; BA, basilar artery; ICA, internal carotid artery; MCA, middle cerebral artery; tCBF, total cerebral blood flow.

index, Clock Draw, and MMSE) was calculated. Composite z-scores in between-group analyses yielded a statistically significant difference between the $\mathrm{AD}$ and NDC groups, with the $\mathrm{AD}$ group being significantly lower [Kruskal-Wallis $=12.00$, $\mathrm{df}=1, P=0.001]$. The magnitude of the difference between the AD and the NDC groups on the composite $z$-score was large (Cohen's $d=3.59$ ). A plot of the individual composite z-score is displayed in Figure 1. No significant difference on composite z-score was found for gender [Kruskal-Wallis $=2.14, \mathrm{df}=1$, $P=0.14]$. However, apolipoprotein E $\varepsilon 4$ carrier status did show a significant difference, with apolipoprotein E $\varepsilon 4$ carriers having lower composite z-scores [Kruskal-Wallis $=6.31$, $\mathrm{df}=1, P=0.01]$. The observed overlap in composite z-scores may represent an ideal opportunity to test the hypothesis in a longitudinal study that individuals in the NDC group exhibiting negative composite z-scores are on a trajectory of swift decline into a clinically demented status.

\section{Discussion}

These data suggest that our AD group had a lower mean pulse pressure than the NDC subjects, and apolipoprotein E $\varepsilon 4$ noncarriers had higher pulse pressures than apolipoprotein $\mathrm{E} \varepsilon 4$ carriers. Cerebral blood flow was reduced in $\mathrm{AD}$ when compared with NDC individuals, and decreased total cerebral blood flow correlated with cognitive dysfunction. In addition, the $\mathrm{AD}$ cohort had lower hippocampal volumes than NDC cases, and the NDC group had higher composite z-scores than the AD subjects. Within the limitations of this study, we discovered some important trends that need to be investigated, in conjunction with other cardiovascular and neurologic risk factors, in a properly powered longitudinal study to establish a brain/cardiovascular fitness index that may aid in the diagnosis of AD.

Higher systolic and pulse pressures have been associated with better cognitive performance in patients with 
Table 6 FreeSurfer volumetric analysis for hippocampal regions of interest

\begin{tabular}{lllll}
\hline & $\begin{array}{l}\text { Absolute left-hippocampus } \\
\text { volume }\end{array}$ & $\begin{array}{l}\text { Absolute right-hippocampus } \\
\text { volume }\end{array}$ & $\begin{array}{l}\text { Relative left-hippocampal } \\
\text { volume }\end{array}$ & $\begin{array}{l}\text { Relative right-hippocampal } \\
\text { volume }\end{array}$ \\
\hline $\mathrm{AD}$ & $2841 \pm 384$ & $3003 \pm 363$ & $1.83 \pm 0.27$ & $1.94 \pm 0.26$ \\
$\mathrm{NDC}$ & $3477 \pm 385$ & $3461 \pm 296$ & $2.41 \pm 0.27$ & $2.40 \pm 0.24$ \\
$P$ value & 0.006 & 0.017 & 0.0008 & 0.003 \\
\hline
\end{tabular}

Notes: Mean \pm standard deviation for absolute (columns 2 and 3) and relative (columns 4 and 5 ) left and right hippocampus volumes for AD patients and NDC subjects. Group difference significances are given in row 4 . The relative hippocampus volume was with regard to the total intracranial volume multiplied by 1000 (which will not affect the assessment of the statistical significance).

Abbreviations: AD, Alzheimer's disease; NDC, nondemented control.

probable AD. ${ }^{47}$ Subclinical dysfunctional heart disease may result in decreased cardiac output that may lead to lower pulse pressure in AD patients. Impaired left ventricular diastolic filling efficiency, as assessed by vortex formation time and detected by echocardiography, was significantly decreased in AD patients compared with NDC subjects. ${ }^{48}$ These findings suggest that intraventricular blood conveyance is suboptimal in AD and that left ventricular diastolic dysfunction is related to cognitive deficits. ${ }^{48}$ Decreased pulse pressure could be part of the pathogenesis of $\mathrm{AD}$ and/or synergistically contribute to the development of this neurodegeneration, given that oligemic and hypoxic changes in the AD brain may also result from destruction of the vasoactive brain centers that regulate cerebral perfusion. ${ }^{49}$ In the elderly, low pulse pressure may also be the consequence of antihypertensive overmedication that results in iatrogenic brain hypoperfusion.

A pathologic complication of hypertension is the development of diffuse microvascular disease. ${ }^{50-52}$ Investigation

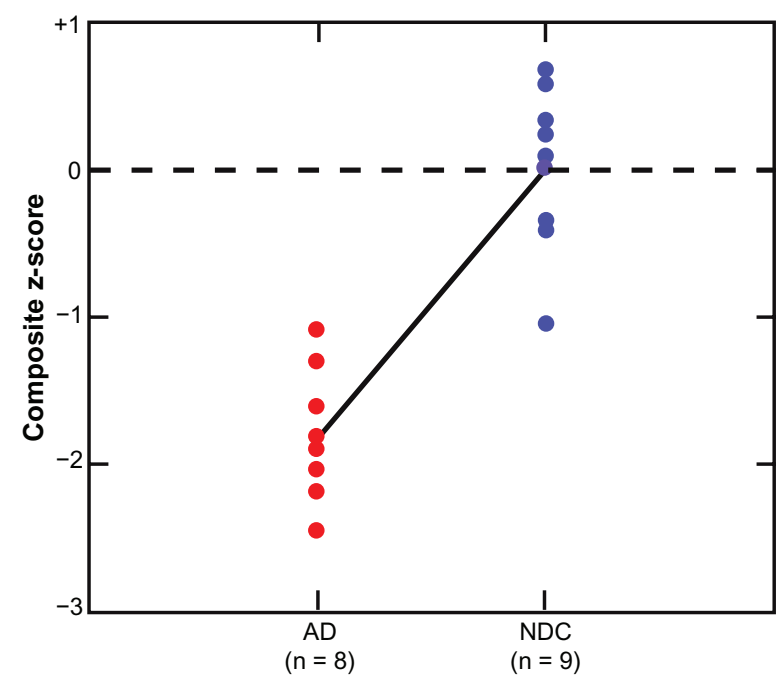

Figure I Mean clinical group and individual differences on the composite z-score. The composite z-score was significantly lower in the AD group $(P<0.001)$.

Notes: Each data point represents an individual's composite z-score average, with each end of the diagonal line representing the mean of each diagnostic group. Abbreviations: AD, Alzheimer's disease; NDC, non-demented control. of the functional conditions of the brain circulation in AD patients by transcranial Doppler ultrasonography of cerebral arteries demonstrated an increased pulsatility index, symptomatic of diffuse microvascular disease, and lower mean flow velocities than subjects with NDC or mild cognitive impairment. ${ }^{53,54}$ In addition, Doppler ultrasound studies have demonstrated a considerable decrease in diastolic velocity along the common and internal carotid arteries in individuals with $\mathrm{AD}$ compared with $\mathrm{NDC},{ }^{53}$ suggesting reduced compliance in the elasticity of these arteries.

Brain hypoperfusion can be triggered or complicated by cardiovascular-related diseases, including stroke, cerebral infarction, hypertension, hypotension, coronary artery disease, myocardial infarction, valvulopathy, arrhythmia, cardiomyopathy, atherosclerosis, arteriosclerosis, diabetes, obesity, and smoking. ${ }^{4,5,55-60}$ The presence of lacunar infarcts and strokes may prompt the onset of dementia or worsen the clinical course of $\mathrm{AD},{ }^{61-64}$ clearly demonstrating that deficiencies in cerebral blood flow are involved in the global pathogenesis of cognitive decline. Arterial stenosis and loss of elastic compliance of the carotid/vertebral vessels, circle of Willis, and major brain arteries, as well as arteriolar and capillary loss are major factors contributing to sustained brain hypoperfusion. ${ }^{56,65}$ Recent pathologic observations by our group and others have suggested that atherosclerosis in the circle of Willis is significantly more extensive in AD when compared with an NDC population. ${ }^{66-71}$ Atherosclerosis, arteriosclerosis, and calcification of arterial walls have been related to cerebral infarcts and increased white matter lesions. ${ }^{72}$ In addition, atherosclerotic calcification measured by computed tomography was found to be associated with impaired cognitive function and decreased brain volume. ${ }^{73}$ Atherosclerosis also creates increased peripheral resistance and consequent age-related elevations in systolic, diastolic, and pulse pressures, leading to brain hypoperfusion and dementia. ${ }^{10,74,75}$ Low systolic and diastolic pressures have also been associated with dementia. ${ }^{76-78}$ In older adults, chronic hypoperfusion caused by lower cardiac output 
has been correlated with white matter hyperintensities and abnormal brain aging. ${ }^{79,80}$ Poor ventricular ejection volume, compounded by loss of arterial compliance, can lower pulse pressure, resulting in deficient brain perfusion and cognitive damage. These harmful pathophysiologic hemodynamic changes are compounded by architectural lesions in the brain microvasculature of $\mathrm{AD}$ subjects, as recently demonstrated by our laboratory. ${ }^{81}$

We recognize that atherosclerosis causes increased peripheral resistance and hence an increase in pulse pressure. Many AD patients, but not all when considered individually, have increased peripheral resistance as reflected by an increased pulsatility index on transcranial Doppler ultrasound resulting from diffuse small vessel disease. ${ }^{53}$ On average, patients with $\mathrm{AD}$ have more extensive atherosclerosis, but a considerable number of cases have a minimal amount. ${ }^{71}$ On the other hand, aging in apparently healthy patients causes an elevation in pulse pressure resulting from increased peripheral resistance due to microvascular lesions and loss of compliance. However, The Baltimore Longitudinal Study of Aging has shown that a number of apparently healthy people 80 years and older have pulse pressures of $40 \mathrm{mmHg}$ or even lower. ${ }^{82}$ In summary, $\mathrm{AD}$ and other dementia syndromes are multifaceted and very heterogeneous maladies associated with general physical decay.

The fact that systolic and pulse pressure are diminished in the $\mathrm{AD}$ group may give the impression of better cardiovascular system conditions. However, the population we examined was an elderly one (mean age 81 years). As a result of atherosclerosis and arteriosclerosis, which are universal in this age group, blood flow to the brain decreases with age and needs to be compensated by an increase in cardiac output which elevates systolic pressure to maintain adequate brain perfusion. Therefore, low pressures do not always represent a healthier status and may result in chronic cerebral metabolic failure, while a slightly compensatory increase in systolic pressure may lead physiologically to better brain and organ perfusion. We recognize the difficult question as to whether deficient cerebral blood flow is a primary cause or consequence of AD. This issue has enormous significance in the context of understanding the pathophysiology AD and in the development of therapeutic interventions.

\section{Conclusion}

The significance of cardiovascular disease and brain hypoperfusion, and their potential impact on disabling neurodegenerative disease, is of paramount epidemiologic importance due to an anticipated explosive increase in the number of individuals over 65 years of age, that will dramatically grow from about 40 million at present to 88.5 million by the year $2050 .{ }^{83}$ The increasing degenerative processes and inability to repair the cardiovascular system observed in the aging population can result in atherosclerosis, arteriosclerosis, arterial stiffness, and endothelial dysfunction, with damage to the blood-brain barrier and brain function. In addition, altered systolic and diastolic pressures and damaged myocardial and valvular performance may impinge on cardiac output. These factors inevitably have a deleterious effect on brain perfusion, resulting in harmful ischemia/hypoxia and neuronal and glial injury. Cardiovascular disease and concomitant failure of cerebrovascular function are major players in the pathogenesis of dementia or at least synergistically participate in the pathophysiology of the disorder. Our data clearly demonstrate significant hemodynamic alterations between AD and NDC subjects. Although limited in size, our pilot data suggest interesting correlations involving cognitive performance, cerebral blood flow, hippocampal volumes, and pulse pressure. We propose to extend this exploratory effort to develop robust cardiovascular indicators of dementia risk or emergence. These observations may have immediate practical implications for dementia management and prevention.

\section{Acknowledgments}

We are in debt to Walter M Kalback and Dean C Luehrs for critical review of the manuscript. We also thank Carolyn Liebsack and Melissa Felix for patient coordination and appointment scheduling. This study was supported by the State of Arizona Alzheimer's Disease Research Consortium and the National Institute on Aging (R01AG019795). The Brain and Body Donation Program is supported by the National Institute of Neurological Disorders and Stroke (U24 NS0702026, National Brain and Tissue Resource for Parkinson's Disease and Related Disorders), the National Institute on Aging (P30 AG19610, Arizona Alzheimer's Disease Core Center), the Arizona Department of Health Services (211002, Arizona Alzheimer's Research Center), the Arizona Biomedical Research Commission (4001, 011, 05-901, and 1001), the Arizona Parkinson's Disease Consortium, and the Michael J Fox Foundation for Parkinson's Research.

\section{Disclosure}

AER, JPD, MMA, KC, JGP, SM, CB, CLM, PT, HM, JMH, TAK, DGW, DGW, JCK, and MB have no competing interests to declare. TGB receives grant/contract support unrelated 
to this work from Lilly, Bayer, and GE. MNS receives grant/ contract support unrelated to this work from Avid, Bayer, Baxter, BMS, Lilly, GE, Janssen, Celegene, Ceregene, and Pfizer. MNS is a consultant/advisor for EASAI, Bayer, Lilly, Avid, Takeda, Amerisciences, and BMS, and receives royalties from Amerisciences and Wiley.

\section{References}

1. [No authors listed]. 2010 Alzheimer's disease facts and figures. Alzheimers Dement. 2010;6(2):158-194.

2. Holmes C, Boche D, Wilkinson D, et al. Long-term effects of Abeta42 immunisation in Alzheimer's disease: follow-up of a randomised, placebo-controlled phase I trial. Lancet. 2008;372(9634): 216-223.

3. Maarouf CL, Daugs ID, Kokjohn TA, et al. The biochemical aftermath of anti-amyloid immunotherapy. Mol Neurodegener. 2010;5(1):39.

4. de la Torre JC. Cerebrovascular and cardiovascular pathology in Alzheimer's disease. Int Rev Neurobiol. 2009;84:35-48.

5. Gorelick PB, Scuteri A, Black SE, et al. Vascular contributions to cognitive impairment and dementia: a statement for healthcare professionals from the American Heart Association/American Stroke Association. Stroke. 2011;42(9):2672-2713.

6. Walters FJM. Intracranial pressure and cerebral blood flow. Physiology. $1998 ; 8: 1-4$

7. Ito H, Kanno I, Fukuda H. Human cerebral circulation: positron emission tomography studies. Ann Nucl Med. 2005;19(2):65-74.

8. Nation DA, Delano-Wood L, Bangen KJ, et al. Antemortem pulse pressure elevation predicts cerebrovascular disease in autopsy-confirmed Alzheimer's disease. J Alzheimers Dis. 2012;30(3):595-603.

9. Vernooij MW, van der Lugt A, Ikram MA, et al. Total cerebral blood flow and total brain perfusion in the general population: the Rotterdam Scan Study. J Cereb Blood Flow Metab. 2008;28(2):412-419.

10. Qiu C, Winblad B, Viitanen M, Fratiglioni L. Pulse pressure and risk of Alzheimer disease in persons aged 75 years and older: a communitybased, longitudinal study. Stroke. 2003;34(3):594-599.

11. Kogure D, Matsuda H, Ohnishi T, et al. Longitudinal evaluation of early Alzheimer's disease using brain perfusion SPECT. J Nucl Med. 2000;41(7):1155-1162.

12. Bradley KM, O'Sullivan VT, Soper ND, et al. Cerebral perfusion SPET correlated with Braak pathological stage in Alzheimer's disease. Brain 2002;125(Pt 8):1772-1781.

13. Johnson NA, Jahng GH, Weiner MW, et al. Pattern of cerebral hypoperfusion in Alzheimer disease and mild cognitive impairment measured with arterial spin-labeling MR imaging: initial experience. Radiology. 2005;234(3):851-859.

14. Alsop DC, Dai W, Grossman M, Detre JA. Arterial spin labeling blood flow MRI: its role in the early characterization of Alzheimer's disease. J Alzheimers Dis. 2010;20(3):871-880.

15. Waddington MM. Section 4: Medial aspect of the cerebral hemispherepericallosal artery and posterior cerebral artery. In: Atlas of Cerebral Angiography with Anatomic Corrections. 1st ed. Boston, MA: Little, Brown and Company; 1974.

16. Hoyer S, Oesterreich K, Wagner O. Glucose metabolism as the site of the primary abnormality in early-onset dementia of Alzheimer type? J Neurol. 1988;235(3):143-148.

17. Hoyer S. The abnormally aged brain. Its blood flow and oxidative metabolism. A review - part II. Arch Gerontol Geriatr. 1982;1(3): 195-207.

18. Kalaria RN, Harik SI. Reduced glucose transporter at the blood-brain barrier and in cerebral cortex in Alzheimer disease. $J$ Neurochem 1989;53(4):1083-1088.

19. Blass JP, Sheu KF, Piacentini S, Sorbi S. Inherent abnormalities in oxidative metabolism in Alzheimer's disease: interaction with vascular abnormalities. Ann N Y Acad Sci. 1997;826:382-385.
20. Tohgi $\mathrm{H}$, Yonezawa $\mathrm{H}$, Takahashi $\mathrm{S}$, et al. Cerebral blood flow and oxygen metabolism in senile dementia of Alzheimer's type and vascular dementia with deep white matter changes. Neuroradiology. 1998;40(3):131-137.

21. Craft S. Insulin resistance and Alzheimer's disease pathogenesis: potential mechanisms and implications for treatment. Curr Alzheimer Res. 2007;4(2):147-152.

22. Caselli RJ, Chen K, Lee W, Alexander GE, Reiman EM. Correlating cerebral hypometabolism with future memory decline in subsequent converters to amnestic pre-mild cognitive impairment. Arch Neurol. 2008;65(9):1231-1236.

23. de la Monte SM. Insulin resistance and Alzheimer's disease. BMB Rep. 2009;42(8):475-481.

24. Craft S. The role of metabolic disorders in Alzheimer disease and vascular dementia: two roads converged. Arch Neurol. 2009;66(3):300-305.

25. Beach TG, Sue LI, Walker DG, et al. The Sun Health Research Institute Brain Donation Program: description and experience, 1987-2007. Cell Tissue Bank. 2008;9(3):229-245.

26. McKhann G, Drachman D, Folstein M, Katzman R, Price D, Stadlan EM. Clinical diagnosis of Alzheimer's disease: report of the NINCDSADRDA Work Group under the auspices of Department of Health and Human Services Task Force on Alzheimer's Disease. Neurology. 1984;34(7):939-944.

27. Folstein MF, Folstein SE, McHugh PR. "Mini-mental state". A practical method for grading the cognitive state of patients for the clinician. J Psychiatr Res. 1975;12(3):189-198.

28. Reisberg B, Ferris SH, de Leon MJ, Crook T. The Global Deterioration Scale for assessment of primary degenerative dementia. Am J Psychiatry. 1982;139(9):1136-1139.

29. Reisberg B. Functional assessment staging (FAST). Psychopharmacol Bull. 1988;24(4):653-659.

30. Borod JC, Goodglass H, Kaplan E. Normative data on the Boston Diagnostic Aphasia Examination, Parietal Lobe battery and the Boston Naming Test. J Clin Neuropsychol. 1980;2:209-215.

31. Rouleau I, Salmon DP, Butters N, Kennedy C, McGuire K. Quantitative and qualitative analyses of clock drawings in Alzheimer's and Huntington's disease. Brain Cogn. 1992;18(1):70-87.

32. Dale AM, Sereno MI. Improved localizadon of cortical activity by combining EEG and MEG with MRI cortical surface reconstruction: a linear approach. J Cogn Neurosci. 1993;5(2):162-176.

33. Dale AM, Fischl B, Sereno MI. Cortical surface-based analysis. I. Segmentation and surface reconstruction. Neuroimage. 1999;9(2): 179-194.

34. Fischl B, Dale AM. Measuring the thickness of the human cerebral cortex from magnetic resonance images. Proc Natl Acad Sci USA. 2000;97(20): 11050-11055.

35. Fischl B, Liu A, Dale AM. Automated manifold surgery: constructing geometrically accurate and topologically correct models of the human cerebral cortex. IEEE Trans Med Imaging. 2001;20(1):70-80.

36. Fischl B, Salat DH, Busa E, et al. Whole brain segmentation: automated labeling of neuroanatomical structures in the human brain. Neuron. 2002;33(3):341-355.

37. Fischl B, Salat DH, van der Kouwe AJ, et al. Sequence-independent segmentation of magnetic resonance images. Neuroimage. 2004; 23 Suppl 1:S69-S84.

38. Fischl B, Sereno MI, Dale AM. Cortical surface-based analysis. II: Inflation, flattening, and a surface-based coordinate system. Neuroimage. 1999;9(2):195-207.

39. Fischl B, Sereno MI, Tootell RB, Dale AM. High-resolution intersubject averaging and a coordinate system for the cortical surface. Hum Brain Mapp. 1999;8(4):272-284.

40. Fischl B, van der Kouwe A, Destrieux C, et al. Automatically parcellating the human cerebral cortex. Cereb Cortex. 2004;14(1):11-22.

41. Han X, Jovicich J, Salat D, et al. Reliability of MRI-derived measurements of human cerebral cortical thickness: the effects of field strength, scanner upgrade and manufacturer. Neuroimage. 2006; 32(1):180-194. 
42. Jovicich J, Czanner S, Greve D, et al. Reliability in multi-site structural MRI studies: effects of gradient non-linearity correction on phantom and human data. Neuroimage. 2006;30(2):436-443.

43. Segonne F, Dale AM, Busa E, et al. A hybrid approach to the skull stripping problem in MRI. Neuroimage. 2004;22(3):1060-1075.

44. Sled JG, Zijdenbos AP, Evans AC. A nonparametric method for automatic correction of intensity nonuniformity in MRI data. IEEE Trans Med Imaging. 1998;17(1):87-97.

45. Segonne F, Pacheco J, Fischl B. Geometrically accurate topologycorrection of cortical surfaces using nonseparating loops. IEEE Trans Med Imaging. 2007;26(4):518-529.

46. Hixson JE, Vernier DT. Restriction isotyping of human apolipoprotein E by gene amplification and cleavage with HhaI. J Lipid Res. 1990;31(3):545-548.

47. van Bruchem-Visser RL, Mattace-Raso FU, van der Cammen TJ. High systolic and pulse pressure levels are associated with better cognitive performance in patients with probable Alzheimer's disease: a crosssectional observational study in a geriatric outpatient population. Dement Geriatr Cogn Disord. 2009;28(4):320-324.

48. Belohlavek M, Jiamsripong P, Calleja AM, et al. Patients with Alzheimer disease have altered transmitral flow: echocardiographic analysis of the vortex formation time. J Ultrasound Med. 2009;28(11):1493-1500.

49. Goadsby PJ, Edvinsson L. Neurovascular control of the cerebral circulation. In: Edvinsson L, Krause DN, editors. Cerebral Blood Flow and Metabolism. 2nd ed. Philadelphia, PA: Lippincott Williams \& Wilkins; 2002.

50. Scuteri A, Nilsson PM, Tzourio C, Redon J, Laurent S. Microvascular brain damage with aging and hypertension: pathophysiological consideration and clinical implications. J Hypertens. 2011;29(8):1469-1477.

51. Brown WR, Thore CR. Review: cerebral microvascular pathology in ageing and neurodegeneration. Neuropathol Appl Neurobiol. 2011;37(1):56-74.

52. Henry-Feugeas MC. Intracranial MR dynamics in clinically diagnosed Alzheimer's disease: the emerging concept of "pulse wave encephalopathy”. Curr Alzheimer Res. 2009;6(6):488-502.

53. Roher AE, Garami Z, Tyas SL, et al. Transcranial Doppler ultrasound blood flow velocity and pulsatility index as systemic indicators for Alzheimer's disease. Alzheimers Dement. 2011;7(4):445-455.

54. Roher AE, Garami Z, Alexandrov AV, et al. Interaction of cardiovascular disease and neurodegeneration: transcranial Doppler ultrasonography and Alzheimer's disease. Neurol Res. 2006;28(6):672-678.

55. de la Torre JC. Carotid artery ultrasound and echocardiography testing to lower the prevalence of Alzheimer's disease. J Stroke Cerebrovasc Dis. 2009;18(4):319-328.

56. de la Torre JC. Vascular risk factor detection and control may prevent Alzheimer's disease. Ageing Res Rev. 2010;9(3):218-225.

57. Dickstein DL, Walsh J, Brautigam H, Stockton SD Jr, Gandy S, Hof PR. Role of vascular risk factors and vascular dysfunction in Alzheimer's disease. Mt Sinai J Med. 2010;77(1):82-102.

58. Moretti R, Torre P, Antonello RM, Manganaro D, Vilotti C, Pizzolato G. Risk factors for vascular dementia: hypotension as a key point. Vasc Health Risk Manag. 2008;4(2):395-402.

59. Roman GC. Vascular dementia prevention: a risk factor analysis. Cerebrovasc Dis. 2005;20 Supp1 2:91-100.

60. Mills S, Cain J, Purandare N, Jackson A. Biomarkers of cerebrovascular disease in dementia. Br J Radiol. 2007;80 Spec No 2:S128-S145.

61. Brundel M, de Bresser J, van Dillen JJ, Kappelle LJ, Biessels GJ. Cerebral microinfarcts: a systematic review of neuropathological studies. J Cereb Blood Flow Metab. 2012;32(3):425-436.

62. Snowdon DA, Greiner LH, Mortimer JA, Riley KP, Greiner PA, Markesbery WR. Brain infarction and the clinical expression of Alzheimer disease. The Nun Study. JAMA. 1997;277(10):813-817.

63. Schneider JA, Wilson RS, Cochran EJ, et al. Relation of cerebral infarctions to dementia and cognitive function in older persons. Neurology. 2003;60(7):1082-1088.
64. Schneider JA, Wilson RS, Bienias JL, Evans DA, Bennett DA. Cerebral infarctions and the likelihood of dementia from Alzheimer disease pathology. Neurology. 2004;62(7):1148-1155.

65. de la Torre JC. Alzheimer's disease prevalence can be lowered with non-invasive testing. J Alzheimers Dis. 2008;14(3):353-359.

66. Roher AE, Esh C, Kokjohn TA, et al. Circle of Willis atherosclerosis is a risk factor for sporadic Alzheimer's disease. Arterioscler Thromb Vasc Biol. 2003;23(11):2055-2062.

67. Roher AE, Esh C, Rahman A, Kokjohn TA, Beach TG. Atherosclerosis of cerebral arteries in Alzheimer disease. Stroke. 2004;35(11 Suppl 1): 2623-2627.

68. Kalback W, Esh C, Castano EM, et al. Atherosclerosis, vascular amyloidosis and brain hypoperfusion in the pathogenesis of sporadic Alzheimer's disease. Neurol Res. 2004;26(5):525-539.

69. Honig LS, Kukull W, Mayeux R. Atherosclerosis and AD: analysis of data from the US National Alzheimer's Coordinating Center. Neurology. 2005;64(3):494-500.

70. Beach TG, Wilson JR, Sue LI, et al. Circle of Willis atherosclerosis: association with Alzheimer's disease, neuritic plaques and neurofibrillary tangles. Acta Neuropathol. 2007;113(1):13-21.

71. Roher AE, Tyas SL, Maarouf CL, et al. Intracranial atherosclerosis as a contributing factor to Alzheimer's disease dementia. Alzheimers Dement. 2011;7(4):436-444.

72. Bos D, Ikram MA, Elias-Smale SE, et al. Calcification in major vessel beds relates to vascular brain disease. Arterioscler Thromb Vasc Biol. 2011;31(10):2331-2337.

73. Bos D, Vernooij MW, Elias-Smale SE, et al. Atherosclerotic calcification relates to cognitive function and to brain changes on magnetic resonance imaging. Alzheimers Dement. April 24, 2012;8(5 Supp1): S104-S111.

74. Tate RB, Manfreda J, Krahn AD, Cuddy TE. Tracking of blood pressure over a 40-year period in the University of Manitoba Follow-up Study, 1948-1988. Am J Epidemiol. 1995;142(9):946-954.

75. Franklin SS, Gustin W, Wong ND, et al. Hemodynamic patterns of age-related changes in blood pressure. The Framingham Heart Study. Circulation. 1997;96(1):308-315.

76. Nilsson SE, Read S, Berg S, Johansson B, Melander A, Lindblad U. Low systolic blood pressure is associated with impaired cognitive function in the oldest old: longitudinal observations in a population-based sample 80 years and older. Aging Clin Exp Res. 2007;19(1):41-47.

77. Morris MC, Scherr PA, Hebert LE, Glynn RJ, Bennett DA, Evans DA. Association of incident Alzheimer disease and blood pressure measured from 13 years before to 2 years after diagnosis in a large community study. Arch Neurol. 2001;58(10):1640-1646.

78. Verghese J, Lipton RB, Hall CB, Kuslansky G, Katz MJ. Low blood pressure and the risk of dementia in very old individuals. Neurology. 2003;61(12):1667-1672.

79. Jefferson AL, Tate DF, Poppas A, et al. Lower cardiac output is associated with greater white matter hyperintensities in older adults with cardiovascular disease. J Am Geriatr Soc. 2007;55(7):1044-1048.

80. Jefferson AL. Cardiac output as a potential risk factor for abnormal brain aging. J Alzheimers Dis. 2010;20(3):813-821.

81. Hunter JM, Kwan J, Malek-Ahmadi M, et al. Morphological and pathological evolution of the brain microcirculation in aging and Alzheimer's disease. PLoS One. 2012;7(5):e36893.

82. Pearson JD, Morrell CH, Brant LJ, Landis PK, Fleg JL. Age-associated changes in blood pressure in a longitudinal study of healthy men and women. J Gerontol A Biol Sci Med Sci. 1997;52(3):M177-M183.

83. Vincent GK, Velkoff VA. The next four decades: the older population in the United States: 2010 to 2050. US Census Bureau P25-1138. Available from: http://www.census.gov/prod/2010pubs/p25-1138.pdf. Accessed September 17, 2012. 
Vascular Health and Risk Management

Dovepress

\section{Publish your work in this journal}

Vascular Health and Risk Management is an international, peerreviewed journal of therapeutics and risk management, focusing on concise rapid reporting of clinical studies on the processes involved in the maintenance of vascular health; the monitoring, prevention and treatment of vascular disease and its sequelae; and the involvement of metabolic disorders, particularly diabetes. This journal is indexed on PubMed Central and MedLine. The manuscript management system is completely online and includes a very quick and fair peer-review system, which is all easy to use. Visit http://www.dovepress.com/ testimonials.php to read real quotes from published authors.

Submit your manuscript here: http://www.dovepress.com/vascular-health-and-risk-management-journal 